\title{
SHOULD THE MUNICIPAL PLAYGROUNDS BE CON- TROLLED BY THE BOARD OF EDUCATION?
}

\section{DWIGHT HEALD PERKINS}

A playground is an outdoor space where boys and girls may play without restriction; where "keep-off-the-grass" signs do not appear; where space for running and jumping and apparatus for play are provided, and where squealing is not prohibited. It differs from a park in that the emphasis is put upon play and not upon the beauties of nature. While growing green must be provided along the borders or in secluded spots, it must always be so arranged as not to interfere with the activities of children nor even be affected by their heedlessness.

Whether playgrounds be controlled by park boards or boards of education is to some degree a minor matter; it is all the municipality. Both are supported by funds raised by taxation imposed upon the citizens, who reap the benefits.

The discussion is, therefore, not one of principle, but one of expediency. It relates to the details of carrying out a scheme the general principles of which I believe we are all agreed upon.

It is admitted that playgrounds must be supervised; that rotation, equal opportunity, and proper use of facilities cannot be left to the children alone; they must be conscious of the presence of some authority. This supervision need not be oppressive, negative, or restrictive. It should be quite the opposite; it should be suggestive and should divert the mind from mischief-making into a line of activity which would cause the mischief-maker to forget his intended pranks. It must always be regarded by children as a privilege to enter a playground, and that privilege must be obtained and retained by proper behavior.

I wish to answer some objections often brought against the control of playgrounds by boards of education. It is often asserted that boards lack funds. This I regard as a temporary objection and not one based upon permanent principles. I see no reason for separating the funds of education from other municipal governing or taxing bodies. If the board cannot raise 
money-and I believe that it can as soon as the public is convinced of the necessity-it would certainly be possible for the municipal government to turn over to the board such amount of money as would be spent by it for playground purposes. With the increased funds from that source the board would be equipped with financial power, and would be in a position to work energetically on this problem.

It is also urged that teachers are already overworked, and that this would place on them an additional burden. I grant that they are overworked, but I think that you will also grant, if we may coin the phrase, that they are "underplayed" (as well as underpaid). I believe that the association of teachers with their pupils while at play would be just as much real recreation for the teachers as it is for the children. I believe that it would be money well spent if sufficient teachers were employed to give them time to direct the children in their play.

The objection, that it would put the playgrounds under the adverse influences of political machinery may be answered. My answer is that this objection insofar as it is true is a reflection only upon those people who stay away from the primaries and the polls and do not take an active part in politics. We may as well admit that we can do nothing to change this situation until we become politicians. We may as well admit that this country is governed, taxes are raised and expended, and public officers are nominated and elected by the people by means of political methods.

I of course assume that civil-service methods of appointment prevail-at least to the extent that they do in Chicago in 1907. I would not advocate playground management under either an educational board or a municipal government unless employees were selected and retained upon merit. If the opposite were the case it would be better to abolish playgrounds altogether.

It is useless to talk of avoiding the politician. If he does not do as he should, we must either take his place or abide the results uncomplainingly. I have had the pleasure of associating with politicians of both parties; men about whom we read uncomplimentary things in the press. I have seen them work energetically and unselfishly for the establishment of playgrounds. In my 
seven years' experience as a member of the special park commission of Chicago I have never received any interference from any politician. So far as my personal experience goes they have always assisted in a patriotic manner in the establishment and maintenance of small parks and playgrounds, and I am sure that their establishment could never have been brought about without such assistance. Aldermen are unpopular in their wards now unless they secure playgrounds for their constituents, and the political value of this movement is appreciated more by them than by outsiders. You should take advantage of that fact.

Playgrounds are not parks. They are for recreation, while parks are for rest. The parks attract a tired person, while playgrounds are for those having undirected and superfluous energy. In the parks one is brought into contact with flowers, shrubs, and trees. Their problem is bringing the country to the people if the people cannot be taken to the country, and it differs widely from that of the playgrounds.

Playgrounds are essentially educational; in fact they are the basis of the development of children. Being educational, they naturally should come under the board of education rather than under park supervision. The objection that is raised in regard to park people being more expert in that line is not an objection that is applicable to playgrounds nor one which should govern in this discussion.

It is said that the hours of school are limited from 9 A. M. to $3: 30$ P. M., and that the grounds are only open from 8 A. M. to 5 P. M. This is a mere matter of administration. I see no reason why the grounds should not be open from 6 A. M. to I I P. M. This does not mean that attendants would have to stay that entire period; it merely means organization. Who would think of limiting our transportation facilities from 8 A. M. to 5 P. M.? They are practically in operation twenty-four hours a day, but their employees work but eight or nine hours each day. There is always a transfer of shifts.

Children are always doing something when they are awake, and there is no reason why their entire time should not be used in a pleasant, natural, and instructive manner. There is also no reason why this cannot be done in a schoolhouse as a neighbor- 
hood center without interfering with the ordinary life or functions of the home. Many of those functions, so far as recreation is concerned, are impossible in the home, and even if they could exist there it would be better to transfer them to the neighborhood center.

I submit the following affirmative reasons in support of the position which I have taken, and I further state that any person may be convinced of the correctness of the affirmative side of this question by reading an article entitled "The Playground as a Part of the Public School," written by Mr. Joseph Lee, of Boston. This and other articles of his contain sufficient argument, I believe, to maintain the position here taken. Several of the points which I have mentioned have been suggested by $\mathrm{Mr}$. Lee's papers.

I know of nothing, unless it be the water and sewerage system, which so completely covers the entire area of the city as the public-school system does. The schools are within walking distance of everybody. As soon as an open prairie is converted into a thickly or even a sparsely inhabited district and the residents are too remote from the school to reach it by walking there is a demand for a new school building, and that demand is complied with just as soon as conditions permit. The schools are not only everywhere, but they represent in value the sum of $\$ 40,000.000 .00$. They belong to the people, and a calculation of the interest lost by the non-use of this investment for one-half or even one-third of the time would convince any business man, I believe, of the wisdom and necessity for making use of this plant twenty-four hours in the day, if that is a possible thing.

It is necessary to the work of the educator. This is true notwithstanding the fact that playgrounds are for all children old enough to walk prior to school age and all children so long as they are able to walk after their school life is over. The less separation between people under and over school age and those in school the better. The special park commission of Chicago has indorsed this contention by locating its playgrounds adjacent to schools wherever possible.

The combining of schools with playgrounds makes possible contact between teachers and pupils through play as well as study relations; each helps the other if the play is not advertised as 
"educational." The relation of play and physical culture to mental and character development should not be broken. There is a great opportunity for co-operation here. The unified organization and management and the avoidance of duplication should appeal to educators, park people, the business man, and taxpayers. No clashing of authority need arise under unified management. This should occur only in the case of dual management. The same would apply to the interference in programmes.

The schools run about nine months in the year. Under this management they should run twelve months in the year. The educational work at the University of Chicago runs twelve months in the year. This does not mean that teachers and students have no vacation, for they do, but there is an opportunity at all times for persons to study there. There should also be an opportunity at all times for pupils to improve by either study or play in the public-school buildings and grounds.

The apparatus could be made to conform to the educational necessities if the board of education had control over the funds with which to provide such apparatus. The providing and maintenance of pet animals and birds could be arranged for so that children might study their habits and enjoy their companionship. This is distinctly an educational feature which would require out-of-door space.

It is not necessary to speak of the educational and characterdeveloping power of flowers. It is said that children wilfully destroy flowers. In answer to this I will say that when the flowers are constantly replaced, and the excitement of a chase or of escaping punishment is taken away, the child gradually loses his motive for destruction and grows into the desire to protect the plants.

In addition to the saving already mentioned is the saving in building construction. There is no reason why the basement of schools should not be used for toilet-rooms, shelters, etc., instead of duplicating them in the playgrounds. A great deal of money could be saved in this way, and as for the destruction of the school property by such use, it can be so built that it would be just as durable as the buildings erected in small parks for use by the public.

Playground space is needed for light and air for buildings. 
It is not wasted, considering the interests of the pupils alone. We must have sunlight in every elementary classroom during some part of the day.

The board of education now, through its physician in the child-study department and through visiting nurses, concerns itself directly and actively in regard to the physical condition of the school children. Through its physical-culture director it develops children's bodies in order that they may become better students. Why should not the physical-culture director, who daily makes use of an indoor gymnasium, for the same reasons make use of an outdoor gymnasium? Why should not the work of the physician be supplemented by such work in the gymnasium as would remedy such defects as may be discovered by the physician.

The teacher's work, in my opinion, is the noblest of all professions. Teachers are, by their training and work, better fitted for the care of children and for the control of their symmetrical development than any other class of persons. It is, therefore, only natural that they would be the best persons who could be obtained to direct and co-operate in the physical exercises indulged in by the children. As a result of such co-operation a cameraderie can be established which will take the place of discipline.

In conclusion, after stating the above reasons for the affirmative side of this question, I wish to fall back for corroboration upon Professor Charles Zueblin of the University of Chicago. On pages 276 and 277 of his book entitled American Municipal Progress the following paragraph appears, which I quote in full, and which I submit as an authorative indorsement of the position which I have taken:

Children's playgrounds are as necessary as schools to the welfare of the modern community. The idea that the public interest in the child ceases at the close of the school session has to be abandoned in the contemporary city. Along with the restricted opportunity for play in the city streets there has come a conception of the value of rational recreation which has its application in both city and country. Regularly equipped playgrounds with apparatus and the direction of skilled teachers or attendants, to encourage both individual and organized play, will soon doubtless be a part of the publicschool system throughout the land. 